\title{
Traumatic optic neuropathy-associated progressive thinning of the retinal nerve fiber layer and ganglion cell complex: two case reports
}

Won June Lee ${ }^{1,2}$, Eun Hee Hong ${ }^{1,3}$, Hae Min Park ${ }^{1,2}$ and Han Woong Lim ${ }^{1,2^{*}}$ (D)

\begin{abstract}
Background: Traumatic optic neuropathy (TON) is a form of optic nerve injury that occurs secondary to trauma and is etiologically associated with acute axonal loss with severe vision loss. Here, we reported longitudinal changes in the peripapillary retinal nerve fiber layer (RNFL) and macular ganglion cell complex (GCC) using wide-field swept source optical coherence tomography (SS-OCT) in two cases of TON and identified the source of the damage.

Case presentation: (Case 1) A 65-year-old man was admitted to the hospital due to an injury in the right eye (OD) and was subsequently diagnosed with indirect TON. He was then treated with high-doses of intravenous steroids. Wide-field SS-OCT was performed at the baseline and after 1 day, 2 days, 1 week, 1 month, and 4 months. The widefield deviation map detected thinning earlier in the macular GCC than in the peripapillary RNFL. (Case 2) A 63-yearold man was admitted to the hospital with a fractured left maxilla-zygomatic complex attributed to blunt-force trauma to the head and loss of vision in his left eye (OS). He was diagnosed with indirect TON and treated with high-doses of intravenous steroids. Wide-field SS-OCT was performed at the baseline and after 1 week, 2 weeks, 2 months 5 months, and 7 months. The wide-field deviation map detected thinning earlier in the peripapillary RNFL than in the macular GCC.

Conclusions: Wide-field SS-OCT facilitated the identification of various sequential progression patterns in patients with TON. Furthermore, the area in which the structural damage was first detected was seen differently in the peripapillary and macular deviation maps for each case. Thus, wide-field imaging, which includes the macular and peripapillary areas, are useful in monitoring TON.
\end{abstract}

Keywords: Traumatic optic neuropathy, Optical coherence tomography, Neuro-ophthalmology

\section{Background}

Traumatic optic neuropathy (TON) is a type of optic nerve injury that occurs secondary to trauma and has been etiologically associated with acute axonal loss with severe vision loss [1]. Indirect TON refers to a variation of TON that is caused by forces transmitted at a distance from the optic nerve after blunt force trauma to the head. This type

\footnotetext{
* Correspondence: limhw@nate.com

'Department of Ophthalmology, Hanyang University Hospital, Hanyang University College of Medicine, 222-1, Wangsimni-ro, Seongdong-gu, Seoul 04763, South Korea

2Department of Ophthalmology, Hanyang University Seoul Hospital, Seoul, South Korea

Full list of author information is available at the end of the article
}

of optic nerve injury is typically observed in the optic canal [2]. Spectral-domain optical coherence tomography (SD-OCT) has been widely used to measure structural changes in the retinal layers, and this technology was used to monitor several retinal diseases and optic neuropathies, including TON [3-5].

Recently, a number of reports have suggested the integration of SD-OCT analyses of the peripapillary and macular areas using an embedded software (PanoMap) or a simultaneous interpretation of both areas to diagnose or determine disease progression in glaucoma [6-8]. Changes in these two areas have also been reported in other non-traumatic optic neuropathies $[9,10]$.

(c) The Author(s). 2019 Open Access This article is distributed under the terms of the Creative Commons Attribution 4.0 International License (http://creativecommons.org/licenses/by/4.0/), which permits unrestricted use, distribution, and reproduction in any medium, provided you give appropriate credit to the original author(s) and the source, provide a link to the Creative Commons license, and indicate if changes were made. The Creative Commons Public Domain Dedication waiver (http://creativecommons.org/publicdomain/zero/1.0/) applies to the data made available in this article, unless otherwise stated. 
Advancements in technology, such as swept-source OCT (SS-OCT), have facilitated the use of wide-field to cover both the peripapillary and macular areas $[6,11,12]$.

A number of studies have clinically demonstrated morphological changes in the thickness of the retinal layer using OCT or scanning laser polarimetry in patients with TON [13-17]. However, only one study has directly compared the thickness of the peripapillary retinal nerve fiber layer (RNFL) with that of the macular ganglion cell complex (GCC) after TON [13]; additionally, to the best of our knowledge, wide-field scanning with SS-OCT in TON has not been reported yet. Comparing the two areas may provide information about the progression and pathophysiology of the disease. Here, we reported longitudinal changes in the peripapillary RNFL and macular GCC using wide-field SS-OCT in patients with TON and identified the area where the damage was first detected.

\section{Case presentation}

(case 1)

A 65-year-old man was admitted to the hospital after he presented with symptoms such as periorbital swelling and bruising in the right eye (OD) caused by blunt force trauma to the head. Despite his injury, he could adequately perform the finger counting test and demonstrated an intraocular pressure (IOP) of $17 \mathrm{mmHg}$ in OD. The slit lamp and fundus examination was normal. His OD demonstrated mid-dilated pupil, along with relative afferent pupillary defect. Computed tomography did not reveal any significant abnormalities, such as bone fractures, except for swelling in the periorbital soft tissue. Following the diagnosis of indirect TON, the patient was immediately treated with high-dose intravenous steroids $(3000 \mathrm{mg}$ of intravenous methylprednisolone in total).

Wide-field SS-OCT was performed at baseline and after 1 day, 2 days, 1 week, 1 month, and 4 months. During the follow-up periods, his IOPs were within the normal range and no further complications occurred. The wide-field thickness map revealed a gradual thinning of the peripapillary RNFL and macular GCC. The widefield deviation map showed that thinning was detected first in the macular GCC than in the peripapillary RNFL (Fig. 1).

\section{(case 2)}

A 63-year-old man was admitted to the hospital with fractured left maxilla-zygomatic complex caused by blunt force trauma to the head. He complained about loss of vision in his left eye (OS), and his visual acuity permitted him to identify hand movements. The IOP in his OS was $20 \mathrm{mmHg}$. The slit lamp and fundus examination was normal. The pupil was normal sized, and relative afferent pupillary defect was observed in OS. Computed tomography showed normal optic nerve and without any of the following features: displaced fracture fragments compressing the optic nerve, hematoma, bleeding in the ethmoid sinus spaces, cerebral injury, and bone fracture in the optic canal. Following the diagnosis of indirect TON, the patient was immediately treated with high-doses of intravenous steroids (3000 mg of intravenous methylprednisolone in total).

Wide-field SS-OCT was taken at baseline and after 1 week, 2 weeks, 2 months, 5 months, and 7 months. During the follow-up periods, IOPs were in the normal

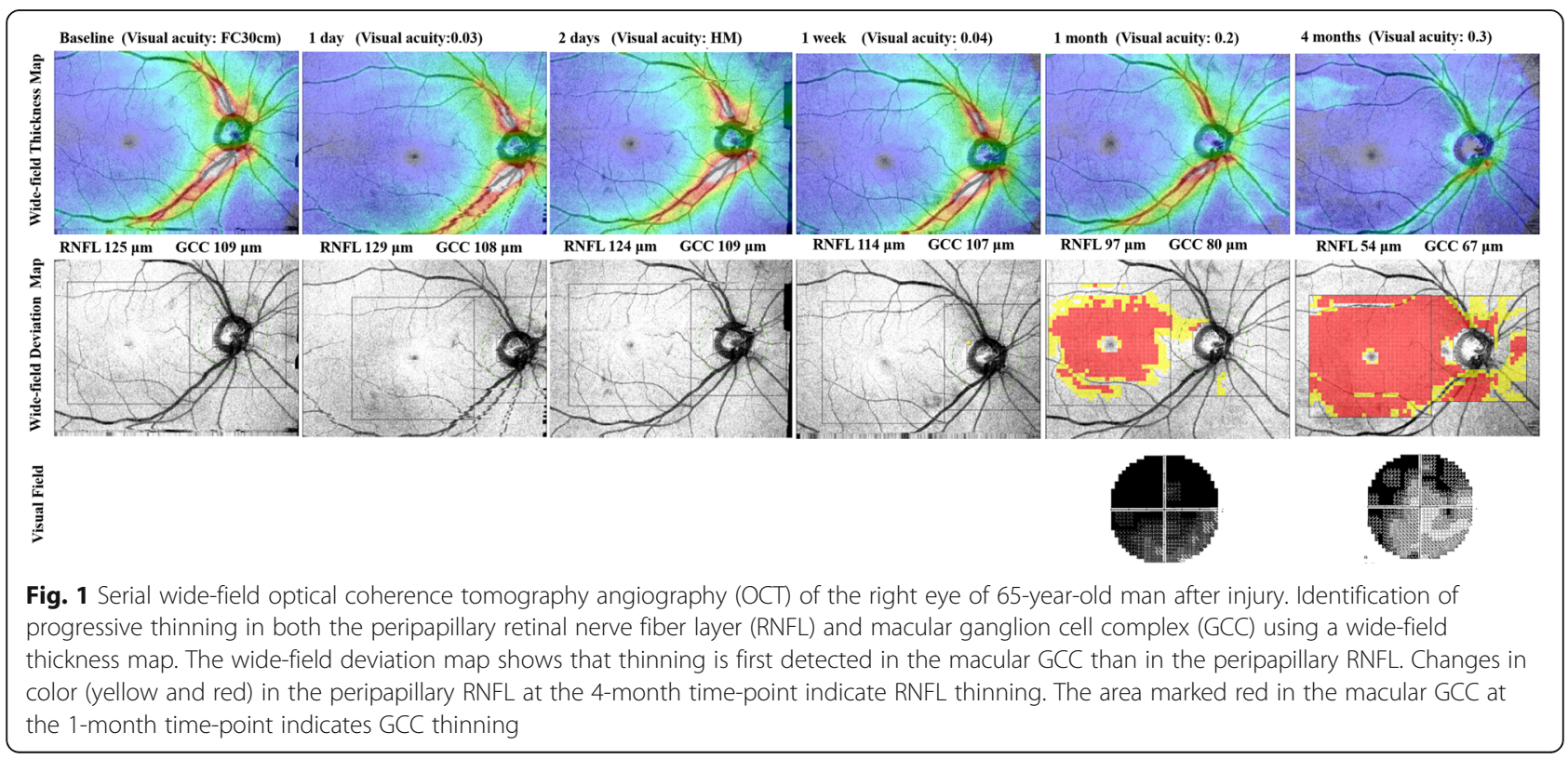


range, and no further complications occurred. The widefield thickness map revealed that the peripapillary RNFL and macular GCC were thinning gradually. The widefield deviation map showed that thinning was detected first in the peripapillary RNFL than in the macular GCC (Fig. 2).

\section{Discussion and conclusions}

In this case report, we presented sequential structural changes associated with TON in both the peripapillary and macular areas over a wide-field area using SS-OCT and identified the area where the damage was detected first. The peripapillary and macular deviation maps revealed differences in the area at which the structural damage was first detected in the two cases. To the best of our knowledge, this is the first study to report the sequential relationship with regard to the areas in TON.

A number of reports have suggested that retinal thinning is detected in TON both at the peripapillary and macular areas [13-17]. However, these studies did not provide sufficient information regarding the area that first demonstrated the damage in TON. One case report that directly compared the thickness of the peripapillary RNFL and GCC after TON demonstrated that the time course of the reduction in the macular area was similar to that observed in the peripapillary RNFL. The authors of the same study suggested that the loss of retinal ganglion cells and related axons continued at rates similar to those of the loss of axonal injury [13].

In the first case, the wide-field deviation map revealed that structural damage was first detected in the macular GCC than in the peripapillary RNFL. Unlike the name of the disease (TON), which indicates that the main lesion of the disease is concentrated in the optic nerve, retinal thinning may first be detected in the macular area. Alternatively, in the second case, wide-field deviation map showed that thinning was detected earlier in the peripapillary RNFL than in the macular GCC. In both cases, the wide-field thickness map showed gradual thinning of the retinal layer in both the peripapillary and macular areas. However, wide-field deviation map, which compared the measured thickness to the embedded normative database, demonstrated that the location where damage is first shown differed depending on the cases.

Considering diseases such as glaucoma where it is imperative to have an accurate judgment of disease progression, several reports have recently investigated the initial point from where the progression of the disease originates and is subsequently detected $[8,18,19]$. Despite several controversial evidences, Kim et al. reported that early glaucomatous structural damage can be observed earlier in the macular ganglion cell-inner plexiform layer (GCIPL) than in the peripapillary RNFL with SD-OCT. $[20,21]$ TON is commonly caused by indirect injury to the optic nerve, which is thought to be the result of a shock that has been transmitted from an orbital impact to the intracanalicular portion of the optic nerve [1]. Although the initial location of the lesion may be different, both diseases are similar to an extent due to the fact that an axonal injury, and not the retinal ganglion cell, may be the point of origin. Therefore, the structural damage associated with TON that was observed in case 1 may also be detected first in the macula.

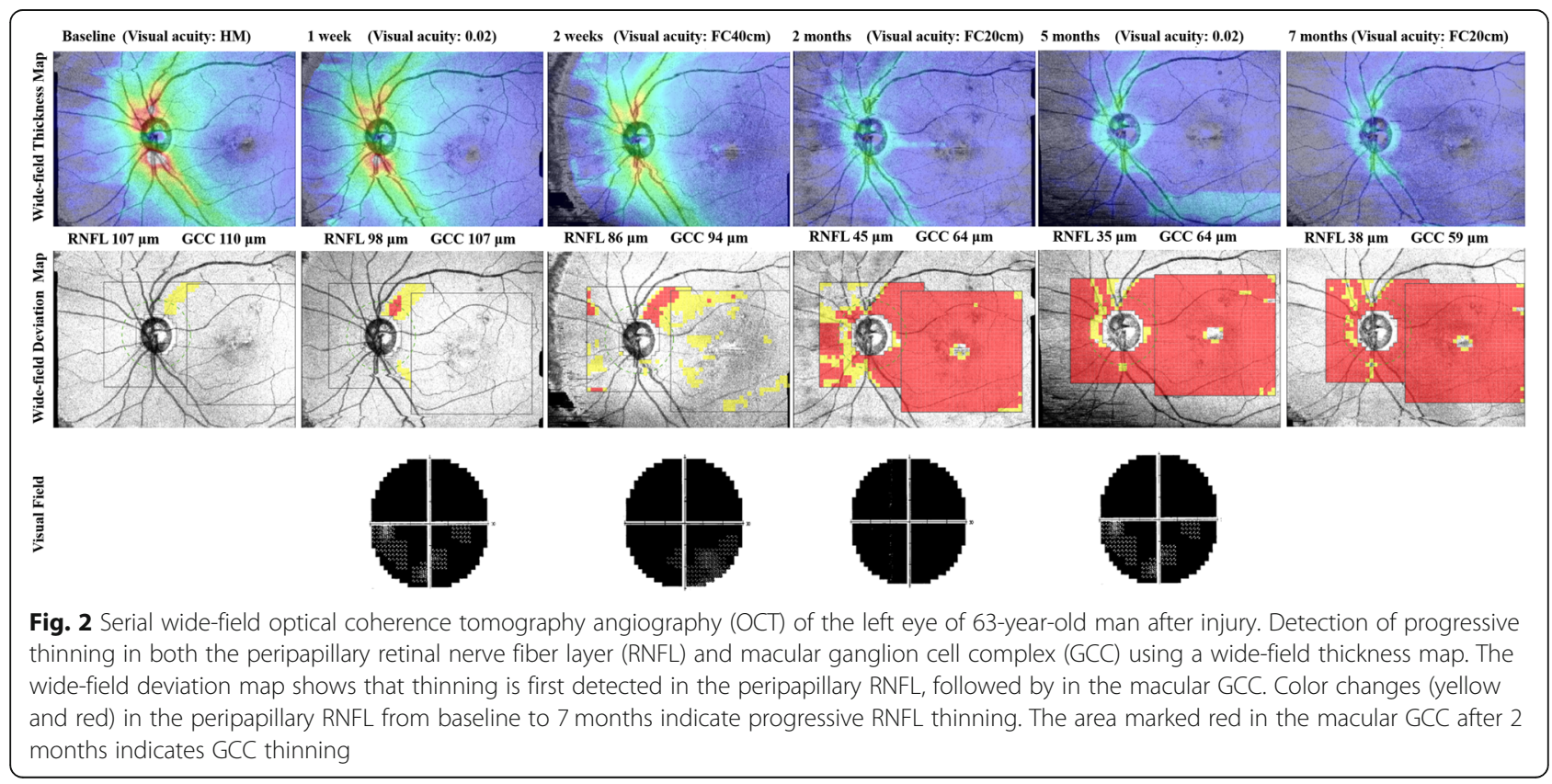


The deviation map visualizes the thinned area comparing with the averaging normative database of the control group, suggesting that the progression of damage over time may differ depending on the baseline anatomical variation in individual patients. In case 2 , the structural damage of TON was detected first in the peripapillary area.

Recently, one group reported that functional damage in TON was well correlated with the macular GCIPL status [14]. In advanced glaucoma, evaluation of the peripapillary RNFL was less clinically useful due to a "floor effect" of the thickness of the RNFL With advanced loss, RNFL thickness never falls below $40 \mu \mathrm{m}$ due to the assumed presence of residual non-neuronal tissues [22]. At this stage of the disease, evaluation of the macular GCIPL using SD-OCT was considered to be a more efficient tool to judge progression [23]. Similarly in TON, OCT images of the macular area could be more useful than those of the peripapillary area to evaluate the functional aspects of the disease.

Wide-field OCT can simultaneously visualize the thickness of the neural tissue in both the peripapillary and macular areas. Therefore, wide-field OCT can be used to specifically identify TON-associated nerve damage and also to obtain information about the progression of TON in a relatively wide area. Unfortunately, relationship between the structural and functional impairments could not be elucidated with only two cases and may be understood in a future study with a larger sample size.

To conclude, in this case report, wide-field SS-OCT allowed us to confirm various sequential progression patterns in patients with TON, along with wide-field imaging of the macula and peripapillary areas, which are useful to monitor TON.

\section{Abbreviations}

GCC: Ganglion cell complex; GCIPL: Ganglion cell - inner plexiform layer; OD: right eye; OS: left eye; RNFL: Retinal nerve fiber layer; SD-OCT: Spectraldomain optical coherence tomography; SS-OCT: Swept-source optical coherence tomography; TON: Traumatic optic neuropathy

\section{Acknowledgments}

Not applicable.

\begin{abstract}
Authors' contributions
Conception and design: WJL, EHH, and HWL; Data collection: WJL, EHH, HMP and $\mathrm{HWL}$; Analysis and interpretation: WJL, EHH, HMP and HWL; writing the article: WJL, EHH, HMP and HWL; Critical revision of the article: WJL, EHH, HMP and HWL; final approval of the article: WJL, EHH, and HWL. All authors have read and approved the manuscript.
\end{abstract}

\section{Funding}

This research was supported by the Bio \& Medical Technology Development Program of the National Research Foundation (NRF) \& funded by the Korean government (MSIT) (No. NRF-2019M3E5D1A01069352). The role of the funding was in the collection and analysis of data and in writing the manuscript.

\section{Availability of data and materials}

The datasets used and/or analyzed during the current study are available from the corresponding author on reasonable request.

\section{Ethics approval and consent to participate}

The local ethics committee ruled that no formal ethics approval was required in this case report.

The authors declare that they adhered to the CARE guidelines.

\section{Consent for publication}

The patients provided written informed consent to publish potentially identifying information and clinical images. The copy of written consent to publish can be made available for the journal.

\section{Competing interests}

The authors declare that they have no competing interests.

\section{Author details}

${ }^{1}$ Department of Ophthalmology, Hanyang University Hospital, Hanyang University College of Medicine, 222-1, Wangsimni-ro, Seongdong-gu, Seoul 04763, South Korea. '2Department of Ophthalmology, Hanyang University Seoul Hospital, Seoul, South Korea. ${ }^{3}$ Department of Ophthalmology, Hanyang University Guri Hospital, Guri, South Korea.

Received: 8 August 2019 Accepted: 31 October 2019

Published online: 07 November 2019

\section{References}

1. Steinsapir KD, Goldberg RA. Traumatic optic neuropathy: an evolving understanding, 2011. Am J Ophthalmol. 151(6):928-933.e922.

2. Miller NR, Newman NJ, Biousse V. Walsh and Hoyt's clinical neuroophthalmology: the essentials, 6th edn: Lippincott and William \& Wilkins, Philadelphia. 2008. p. 195-201.

3. Adhi M, Duker JS. Optical coherence tomography--current and future applications. Curr Opin Ophthalmol. 2013;24(3):213-21.

4. Huang D, Swanson EA, Lin CP, Schuman JS, Stinson WG, Chang W, Hee MR, Flotte T, Gregory K, CAJs P. Optical coherence tomography. Science. 1991; 254(5035):1178-81.

5. Nassif N, Cense B, Park B, Pierce M, Yun S, Bouma B, Tearney G, Chen T, JJOe DB. In vivo high-resolution video-rate spectral-domain optical coherence tomography of the human retina and optic nerve. Opt Express. 2004;12(3):367-76

6. Hood DC. Improving our understanding, and detection, of glaucomatous damage: an approach based upon optical coherence tomography (OCT). Prog Retin Eye Res. 2017;57:46-75.

7. Lee WJ, Kim TJ, Kim YK, Jeoung JW, Park KH. Serial combined wide-field optical coherence tomography maps for detection of early glaucomatous structural progression. JAMA Ophthalmol. 2018;136(10):1121-7.

8. Lee WJ, Na Kl, Ha A, Kim YK, Jeoung JW, Park KH. Combined use of retinal nerve Fiber layer and ganglion cell-inner Plexiform layer event-based progression analysis. Am J Ophthalmol. 2018:196:65-71.

9. Asanad S, Tian JJ, Frousiakis S, Jiang JP, Kogachi K, Felix CM, Fatemeh D, Irvine AG, Ter-Zakarian A, Falavarjani KG, et al. Optical coherence tomography of the retinal ganglion cell complex in Leber's hereditary optic neuropathy and dominant optic atrophy. Curr Eye Res. 2019;44(6):638-44.

10. Miki A, Endo T, Morimoto T, Matsushita K, Fujikado T, Nishida K. Retinal nerve fiber layer and ganglion cell complex thicknesses measured with spectral-domain optical coherence tomography in eyes with no light perception due to nonglaucomatous optic neuropathy. Jpn J Ophthalmol. 2015;59(4):230-5.

11. Lee WJ, Na KI, Kim YK, Jeoung JW, Park KH. Diagnostic ability of wide-field retinal nerve Fiber layer maps using swept-source optical coherence tomography for detection of Preperimetric and early Perimetric Glaucoma. J Glaucoma. 2017:26(6):577-85.

12. Lee WJ, Oh S, Kim YK, Jeoung JW, Park KH. Comparison of glaucomadiagnostic ability between wide-field swept-source OCT retinal nerve fiber layer maps and spectral-domain OCT. Eye (London, England). 2018;32(9): 1483-92.

13. Kanamori A, Nakamura M, Yamada $Y$, Negi A. Longitudinal study of retinal nerve fiber layer thickness and ganglion cell complex in traumatic optic neuropathy. Arch Ophthalmol (Chicago, III: 1960). 2012;130(8):1067-9.

14. Lee JY, Cho K, Park KA, Oh SY. Analysis of retinal layer thicknesses and their clinical correlation in patients with traumatic optic neuropathy. PLoS One. 2016;11(6):e0157388 
15. Medeiros FA, Moura FC, Vessani RM, Susanna R Jr. Axonal loss after traumatic optic neuropathy documented by optical coherence tomography. Am J Ophthalmol. 2003;135(3):406-8.

16. Medeiros FA, Susanna R Jr. Retinal nerve fiber layer loss after traumatic optic neuropathy detected by scanning laser polarimetry. Arch Ophthalmology (Chicago, III: 1960). 2001;119(6):920-1.

17. Vessani RM, Cunha LP, Monteiro ML. Progressive macular thinning after indirect traumatic optic neuropathy documented by optical coherence tomography. Br J Ophthalmol. 2007;91(5):697-8.

18. Hou HW, Lin C, Leung CK. Integrating macular ganglion cell inner Plexiform layer and Parapapillary retinal nerve Fiber layer measurements to detect Glaucoma progression. Ophthalmology. 2018;125(6):822-31.

19. Marshall HN, Andrew NH, Hassall M, Qassim A, Souzeau E, Ridge B, Nguyen T, Fitzgerald J, Awadalla MS, Burdon KP, et al. Macular ganglion cell-inner Plexiform layer loss precedes Peripapillary retinal nerve Fiber layer loss in Glaucoma with lower intraocular pressure. Ophthalmology. 2019.

20. Kim YK, Jeoung JW, Park KH. Inferior macular damage in Glaucoma: its relationship to retinal nerve Fiber layer defect in macular vulnerability zone. J Glaucoma. 2017;26(2):126-32.

21. Kim YK, Ha A, Na Kl, Kim HJ, Jeoung JW, Park KH. Temporal relation between macular ganglion cell-inner Plexiform layer loss and Peripapillary retinal nerve Fiber layer loss in Glaucoma. Ophthalmology. 2017;124(7): 1056-64.

22. Hood DC, Kardon RH. A framework for comparing structural and functional measures of glaucomatous damage. Prog Retin Eye Res. 2007;26(6):688-710.

23. Shin JW, Sung KR, Lee GC, Durbin MK, Cheng D. Ganglion cell-inner Plexiform layer change detected by optical coherence tomography indicates progression in advanced Glaucoma. Ophthalmology. 2017;124(10): 1466-74.

\section{Publisher's Note}

Springer Nature remains neutral with regard to jurisdictional claims in published maps and institutional affiliations.

Ready to submit your research? Choose BMC and benefit from:

- fast, convenient online submission

- thorough peer review by experienced researchers in your field

- rapid publication on acceptance

- support for research data, including large and complex data types

- gold Open Access which fosters wider collaboration and increased citations

- maximum visibility for your research: over $100 \mathrm{M}$ website views per year

At $\mathrm{BMC}$, research is always in progress.

Learn more biomedcentral.com/submissions 